\title{
LA FORMACIÓN GERONTOLÓGICA EN TRABAJO SOCIAL EN URUGUAY. IDAS Y VUELTAS O LOS VAIVENES DEL CAMPO
}

\section{GERONTOLOGICAL TRAINING IN SOCIAL WORK IN URUGUAY. BACK AND FORTH OR THE UPS AND DOWNS OF THE FIELD}

Fecha recepción: agosto de 2019 / fecha aceptación: noviembre de 2019

Sandra Sande Muletaber

Cómo citar este artículo:

Sande, S. (2019). La formación gerontológica en trabajo social en Uruguay. idas y vueltas o los vaivenes del campo. Revista Pensamiento y Acción Interdisciplinaria, 5(2), 84-101. DOI: http://doi.org/10.29035/pai.5.2.84

\begin{abstract}
Resumen
Este artículo pretende dilucidar sobre la formación en la especificidad de la vejez y el envejecimiento en tanto área de inserción del Trabajo Social que debe ser formalizada en el currículo de la disciplina. Se propone poner en debate la necesidad de generar espacios de conocimiento e investigación sobre la especificidad de la temática en el ámbito el Trabajo Social. Se plantea la historicidad de la inserción profesional en ese campo y su vinculación con la formación disciplinar.
\end{abstract}

Palabras claves: formación académica, Trabajo Social, Vejez.

\begin{abstract}
This article aims to elucidate on training in the specificity of old age and ageing in both area's inclusion of Social work which should be formalized in the curricula of the discipline. It is proposed to put in discussion the need for generating spaces of knowledge and research on the specificity of the topic in the Social work field. Raises the historicity of the professional insertion in that field and its link with the training discipline.
\end{abstract}

Keywords: academic background, old-age, Social work.

1 Trabajadora social, uruguaya. Doctora en Ciencias Sociales, opción Trabajo Social de la Udelar. Magister en Trabajo Social de la Udelar, Magister en Psicogerontología, Universidad Maimónides, Argentina, Licenciada en Trabajo Social, Licenciada en Sociología por la Udelar. Docente del departamento de Trabajo Social de la Udelar. Montevideo, Uruguay. Correo electrónico: sandrasande@hotmail.com 


\section{Introducción}

El abordaje de la Vejez y el envejecimiento ha sido un área de ejercicio e intervención profesional histórica del Trabajo Social en Uruguay, sin embargo no ha sido un campo de saber suficientemente sistematizado desde la disciplina y menos aún objeto de formación a nivel de la academia, hasta hace relativamente poco tiempo.

Es en el año 2007 que surge, en el marco de la materia Metodología de la Intervención Profesional nivel $\operatorname{dos}^{2}$ (MIP 2) del plan 1992, un acuerdo con el subprograma adulto mayor del $\mathrm{APEX}^{3}$ un centro de práctica vinculado a la salud familiar (2007/2008) con especificidad en población vieja. A partir de esa experiencia y contando con docentes que tenían un acumulado en la temática, fundamentalmente a partir de su experiencia profesional, durante los años 2009 y 2010 la encargada de la cátedra plantea un espacio de supervisión específico en la temática, incorporando centros de práctica vinculados a grupos de viejos que se reunían en los diferentes territorios.

Con el advenimiento del nuevo plan de estudio de la carrera de trabajo social (Universidad de la República, 2009) se modifica la curricula y la formación específica en la intervención profesional pasa a estar centrada en la conformación de Proyectos Integrales (PI). Estos se encuentran incluidos en el eje de las Metodologías de la Intervención Profesional "que es una continuación de Trabajo Social del Ciclo Básico y que atraviesa todo el proceso de formación". En estos cursos, que "son de enseñanza activa, se concentra la formación específica requerida en los procesos de trabajo de nuestros profesionales y actúan como articuladoras del conjunto de asignaturas que confluyen en la formación general del estudiante" (Universidad de la República, 2009).

Es ese marco surge la conformación del Proyecto Integral "Cuidado Humano, Derechos e Inclusión social" la iniciativa de generar un espacio de formación específica en el área, lo cual se plantea ya desde el inicio del PI, creando un área de vejez y envejecimiento que permitiera a los estudiantes realizar sus prácticas pre profesionales vinculadas a esta población.

Concomitantemente y tomando como base los análisis realizados sobre la pertinencia de debatir e interpelar a la vejez como área de conocimiento se crea el Área de vejez y Trabajo Social (Avyts) incluyendo a docentes del departamento de Trabajo Social de la Facultad de ciencias sociales, estudiantes avanzados del PI y profesionales que, interesados en la temática, estuvieran insertos en el trabajo

2 La materia es parte de la formación específica del estudiante de grado quien debe realizar su experiencia de práctica pre profesional en territorios, instituciones y organizaciones. La docente histórica de esa cátedra es la Profa. Teresa Dornell, fundadora del Área de Vejez y envejecimiento desde el Trabajo Social (Avyts)

3 Es un Programa interdisciplinario integral de proyección comunitaria de la Universidad de la República (UdelaR), que "procura la concurrencia conjunta integrada y coordinada de los servicios universitarios al espacio comunitario, asociando indisolublemente la enseñanza, asistencia, investigación y extensión. Su área de intervención se circunscribe a los límites geográficos del Municipio A de Montevideo. http://www.universidad.edu.uy/prensa/render/tem/itemld/42785 
con la vejez. ${ }^{4}$ La propuesta se inicia en el año 2011 a partir de la concreción de un espacio de supervisión y se desarrolla a partir de debates que se van coconstruyendo en el colectivo, generando insumos para su problematización, visibilización y enunciación. El área permitió aportar insumos desde la academia a una temática que en la profesión no había estado en la agenda.

En la actualidad, avanzados en el proceso de formación gerontología desde área de vejez y trabajo social, se plantea la necesidad de sistematizar las experiencias del proceso de enseñanza-aprendizaje tanto a nivel de grado, como en las experiencias de formación permanente de los profesionales a partir de los cursos ofrecidos por el área ${ }^{5}$. Para ello se pretende generar un proceso de investigación que tome los insumos que se han ido desarrollando en estas instancias.

Este artículo pretende dar cuenta de las implicancias que la propuesta de una formación en el área de la vejez y el envejecimiento, en el currículo de grado de los estudiantes de la carrera de trabajo social, tiene en la conformación de profesionales que pongan en debate las representaciones socio-simbólicas de la Vejez. El propósito que guío su incorporación fue que una vez egresados de la carrera sean capaces de descifrar y deconstruir los sistemas y movimientos de objetivación- subjetivación de las personas mayores a partir de una problematización basada en una perspectiva de derechos. A esto se suma la idea de que los aportes que la gerontología pensada desde la disciplina, contribuya a la apertura de diálogos fluidos e interpelantes que aporten al debate desde una perspectiva que permita avanzar a una superación de las fragmentaciones y el aislamiento (Mauros 2014) que la temática ha concitado en la profesión.

Se procura que 6 luego de ocho años de creada el área, la sistematización de las investigaciones e intervenciones desde el campo de la vejez produzcan información sobre la fortaleza de los instrumentos y las prácticas educativas planteadas.

Se trata de un avance sobre una investigación en proceso, que tomará como muestra los documentos académicos originados por los estudiantes de grado y posgrado, así como datos producidos por los docentes a partir de cuestionarios implantados durante los cursos de grado y formación permanente.

\footnotetext{
4 Sobre este tópico se realizaron varias ponencias por parte del equipo en diferentes instancias como por ejemplo en las IX JORNADAS JIDEEP FTS / UNLP o en las XIII Jornadas de Investigación de la Facultad de Ciencias Sociales, UdelaR, Montevideo, a efectos de dar a conocer el área.

http://www.trabajosocial.unlp.edu.ar/uploads/docs/gt21_area_de_vejez_y_trabajo_social_una_aproximacion_al_debate_en_uruguay_.pdf

5 Desde el año 2012 se desarrollan cursos sobre vejez y envejecimiento en el marco del Programa de Educación Permanente de la Udelar, tanto en Montevideo como en el resto del país.

6 Esto estaba ya en el espíritu de la creación del Área de Vejez y Trabajo Social, ver:

http://cienciassociales.edu.uy/wp-content/uploads/2014/09/Mauros.pdf
} 


\section{Contextualización de la sociedad para la cual estamos formando profesionales del Trabajo Social}

Uno de los debates que se van construyendo en el área tiene que ver con la forma en que se describe a las sociedades actuales. Durante la formación los estudiantes reciben diferentes perspectivas teóricas a partir de las cuales, se propone, puedan posicionarse reflexivamente.

La perspectiva de los teóricos de la modernidad reflexiva7, postradicional o del riesgo plantea que a las sociedades actuales se las puede pensar como un conjunto de narrativas que ordenan la vida social que tiene una fuerza tal, que a nivel simbólico se manifiesta como certeza. La eficacia simbólica de estos relatos en su reproducción colectiva, que se adecua a los tiempos, permite el mantenimiento del orden social (Giddens, 1997). La etapa de radicalización de la modernidad, a la que asistimos, muestra como las formas tradicionales se cuestionan y ya no tienen valor prescriptivo por lo que dejan a las personas examinando constantemente las prácticas sociales, las cuales son reformadas toda vez que a la luz de nueva información sobre esas mismas prácticas, alternan su carácter constituyente.

Es en ese sentido que para esta perspectiva, la modernidad reflexiva a partir de los mecanismos de desanclaje, la separación del tiempo y el espacio y la apropiación reflexiva del conocimiento, habilitan una libertad mayor que en épocas anteriores (Giddens,1995).

En las sociedades "se han producido y se están produciendo cambios en los arreglos familiares, surgiendo nuevas formas de familia (ensamblada, monoparental, homoparentales)" (Sande, 2016 p.143). El pronunciamiento hegemónico platea estas transformaciones familiares como novedosas y que traen aparejadas consecuencias negativas sobre las personas y sobre las propias familias. Se propone que estas "nuevas" conformaciones afectan los vínculos entre progenitores y descendientes, que mellan la convivencia "normal" de las familias y que tienen consecuencias sobre las identidades individuales. ${ }^{8}$

Este discurso obvia que las supuestas transformaciones se subsumen en prácticas históricas, siempre hubo diferentes arreglos familiares, familias extendidas, monoparentales, ensambladas, basta ver los viejos cuentos infantiles ${ }^{9}$. La transformación de la intimidad (Giddens, 2000) producto del proyecto reflejo, modifica la forma en que las personas problematizan los vínculos y plantea la posibilidad de desmercantilizar la idea de familia. O sea, "es por necesidad, en cierto modo, una

7 Sobre este tema ver, Sande Muletaber, S. en Paola, J. (2015) Más mayores, más derechos Diálogos interdisciplinarios sobre vejez http://www.ts.ucr.ac.cr/binarios/libros/libros-000057.pdf

8 Para este tópico se recomienda la lectura de Quintero Velázquez: La perspectiva de género y las nuevas organizaciones familiares

9 La madrastra de cenicienta, la madre sola de caperucita, la migración de la madre de Marco, o la abuelidad o la paternidad de Geppeto. 
lucha contra las influencias mercantilizadoras, aunque no todos los aspectos de la transformación en mercancía le sean hostiles" (Giddens, 1997, p.253).

Pero estos postulados, si bien tienen una fuerza tal que acompaña las propuestas de mayores derechos para las personas, tiene su contracara. Zizek (1998) "menciona que la familia constituye la comunidad "orgánica" primordial de los individuos" (p.139). Es decir, las personas parten del seno en que nacen y esta es la base de un complejo proceso de identificación mayor (que llama secundaria). Para este autor la lógica del capitalismo global implica una nueva forma de "cruzada" valiéndose de los mismos argumentos: La normalización de una única forma de familia, que apela a la figura "típica", funcional-parsoniana. Esto se puede verificar en las respuestas de la derecha frente a la avanzada de derechos, la Argentina presenta por enésima vez el proyecto de despenalización del aborto, en Chile las luchas universitarias siguen siendo reprimidas, Brasil avanza en pérdida de derechos de los colectivos de la diversidad, Donald Trump lidera la lucha contra "la ideología de género".

Las propuestas de Estados progresistas en términos de defensa de derechos, de las luchas de la sociedad civil organizada se ven amenazadas por corrientes de pensamiento que pregonan la vuelta a los "valores" a partir de la utilización de "figuras típicas" y de la idea de "universalismo" (Zizek, 1998) como los son las nociones del sexo genético, la figura de la madre abnegada, la idea de familia "normal". La permanencia de una perspectiva de derechos en el marco de los Estados es una cuestión de correlación de fuerzas y así como se consagran pueden verse amenazados, basta con ver los que sucede en Brasil con respecto a los derechos de la comunidad LGTBIQ.

Como trabajadores sociales los estudiantes, a su egreso se emplearán fundamentalmente en el Estado ${ }^{10}$; de ahí que la problematización de las políticas sociales es un imperativo. Si se considera que las manifestaciones de la cuestión social ${ }^{11}$ en la actualidad, al decir de Rozas (2001), no podría leerse sin tener en cuenta el problema que la produce, la relación capital-trabajo y las transformaciones de las formas de producción y reproducción en la lógica del capitalismo global.

Las transformaciones que se han generado en los sistemas de producción y en la rotación y velocidad de recuperación del capital (...) han cambiado sin duda las condiciones del trabajo y la reproducción del capital. Como producto de ese proceso de reestructuración se han generado niveles de precarización laboral, desocupación, vulnerabilidad, marginalización, empobrecimiento y exclusión (Rozas, 2001, p. 9).

10 El Primer censo de egresados de Trabajo social muestra que para el 60\% de los trabajadores sociales el empleador principal es el Estado (Claramount, 2015)

11 Entendiendo cuestión social como el conjunto de problemas sociales, políticos y económicos que se generan con el surgimiento de la clase obrera en la sociedad capitalista, ver: Castel (1997), Netto (1997), lamamoto (1997) 
Estas consecuencias se viven en la cotidianidad de las vidas de las personas y tiene su correlato en las prácticas. Zizek (1998) advierte que las crisis económicas, como relato del capitalismo, legitiman que los gobiernos apelen a políticas restrictivas, de recorte del gasto, y que estas respuestas no estarían ya vinculadas a los Estados-Nación sino que serían el resultado de la internacionalización del capital en tanto "El desmantelamiento del Estado de Bienestar es el resultado de la ruptura del equilibrio de la lucha de clases hacia el capital" (Zizek, 1998, p.1251). ${ }^{12}$

Este desequilibrio genera que se constituyan sectores excluidos de los beneficios sociales - los marginales (Zizek, 1998), los perdedores de la individualización configurados como individuos por defecto (Castel, 2010) - a quienes la modernidad reflexiva ha dejado de lado.

No obstante, poco a poco, aunque la toma de conciencia fue lenta, resultó que no se atravesaba una zona de turbulencias pasajeras y que no bastaba con ajustarse el cinturón antes de volver a empezar con la "recuperación". De hecho, y hoy en día estamos en mejores condiciones de comprenderlo, lo que se jugó a lo largo de estos últimos treinta años es un cambio de régimen del capitalismo. (Castel, 2010: 16).

La ideología dominante, como se señala Sande (2016) "establece como superada la idea de disputa de clases y da paso a una forma post ideológica en que los consensos negociados dan lugar a una administración racional de lo social, junto con la proliferación de distintas formas de vida" (p.145). Por consiguiente, la actitud tolerante que esconde formas de discriminación es «el síntoma del capitalismo tardío multiculturalista» (Zizek, 1998, p.157).

Por otra parte, agregar que,

la concepción del multiculturalismo planteada por Zizek como una forma de racismo, de diferenciación negativa con el otro, conlleva a mecanismos de exclusión cada vez mayores y a que la respuesta sea alcanzar un modo de pensar capaz de dar cuenta en forma simultanea de los rasgos funestos y a la vez del poder liberador del dinamismo del capitalismo tardío (Sande,2016, p.150)

Desde distintas perspectivas estos autores dan una lectura de la sociedad actual que habilita "tomas de posición" ¿Cuál es el rol del Trabajo Social si nos paramos desde estos diagnósticos? 
Si le agregamos una nueva interpelación a la comprensión de las sociedades actuales se complejiza más aún la respuesta. Las intervenciones desde la profesión no solo tienen que estar mediadas por una sólida base teórica y procedimental, sino que deben incorporar un posicionamiento ético y político.

Jameson (1992) plantea que la política «es el acto de escoger quienes son tus amigos y quienes tus enemigos» (p.12), en tiempos de crisis de movilización en torno a las reivindicaciones vinculadas a la lucha de clase surgen movimientos sociales con nuevas bases. En Uruguay la marcha del 8 de Marzo congrega muchísimas más personas que el 1 de Mayo. ¿Se trata de una ruptura con las "viejas" formas de lucha? ¿Se está dejando de lado la búsqueda de la emancipación humana? ¿La contradicción capital-trabajo se subsume en los procesos de individuación y la construcción de un proyecto reflejo?

La respuesta de Jameson es que se debe buscar la forma de mapear estas nuevas luchas en torno a lo que es "un peligro común" y apela a presentar la noción de lucha de clases de manera innovadora, es lo que denomina "lucha de discurso".

Los nuevos movimientos sociales en torno a las reivindicaciones de género, diversidad, ecología, son otras tantas maneras de politizar la nueva cuestión social que no pueden dejarse de lado.

De esta manera, "frente a la despolitización de la economía, es necesaria la repolitización como un requerimiento para imponer" (Sande 2014, p.18). En una línea similar el planteo de Zizek es que, "alguna limitación radical de la libertad del capital» constituyéndose en el único modo de generar efectivamente una sociedad en la cual las decisiones riesgosas para el largo plazo surjan de un debate político que incluya a todos los interesados" (2001, p. 376).

\section{Sobre la enseñanza de la práctica profesional}

El profesional del Trabajo Social se inserta en el campo profesional como trabajador asalariado que implementa, diseña, ejecuta y /o planifica de acuerdo a las orientaciones del Estado a partir de las Políticas Públicas, como uno de sus cometidos principales.

Para ello es necesario fomentar la capacidad de compromiso ético institucional, a partir de la incorporación de competencias profesionales que den cuenta de la especificidad de la profesión, incorporando la articulación con lo interdisciplinario, formando profesionales con autonomía y sentido crítico fundamentados en una sólida base de teoría. 
La propuesta planteada por el Plan de estudios 2009 pretende que a partir de lo incorporado durante la carrera, y especialmente vinculado a los contenidos de la formación específica en Trabajo Social, al egreso de los profesionales "su práctica se orientará por la honestidad y creatividad intelectual, integrando críticamente en su desempeño específico la complejidad del entorno en el que está inserto" (Universidad de la República, 2009).

El actual plan de estudios implica que el ciclo profesional cuente con 8 módulos con créditos obligatorios y optativos, que suponen la posibilidad de una formación básica del estudiante, el que puede desarrollar un perfil específico según su interés, incorporando la noción de integralidad. La inscripción de la propuesta de los Proyectos Integrales (PI) intenta permitir la formación en teoría y metodología vinculada a la intervención profesional.

El modulo Fundamentos teórico metodológicos del trabajo social concentra la formación específica a nivel disciplinar. Es también donde se incluye el aprendizaje de la práctica pre-profesional, a través de la inclusión de estudiantes en proyectos de equipos docentes que articulan enseñanza, investigación y extensión a partir de los PI.

Tras diez años de implementación del plan, se han creado seis proyectos integrales: Trabajo y Cuestión Agraria, Sujetos Colectivos y Organización popular, Hábitat y Territorio, Cuidado Humano, y Protección Social, Instituciones y Práctica, e Infancia. Para el año 2019 están vigentes cuatro PI., habiendo cerrado dos. El aporte que a la enseñanza de grado en Trabajo Social le ha brindado esta forma de trabajo impacta en la conformación de equipos estables de docentes que pueden realizar acumulaciones teóricas a partir de los diferentes espacios (investigación, supervisión, teóricos y extensión) y al estudiante, la posibilidad de desarrollar una trayectoria de acuerdo a sus propios intereses.

En este proceso, el propio plan de estudio y sobre todo la fundamentación del módulo impartido, debe ser tomado como objeto de reflexión de los docentes para buscar mejoras sustanciales en el proceso de enseñanza-aprendizaje. Es necesario hacer una interpretación y lectura del proceso que permita engendrar propuestas sobre cómo mejorarlo, contando con un arsenal apropiado de recursos que apoyen esas decisiones y el quehacer pedagógico (Díaz Barriga, 2005).

Reflexionar sobre cómo el propio derrotero de la experiencia cotidiana ha ido generado cambios, algunos sutiles, otros de forma y algunos de contenido, de los propios programas, incorporando perspectivas, herramientas pedagógicas, tecnologías, para intentar dar cuenta de los intereses tanto de la academia, como de la realidad social, teniendo en cuenta el tipo de estudiante que ingresa a la carrera, y su formación previa. 
Lejos estamos de pensar que toda propuesta de cambio realmente le imprime un rumbo diferente al trabajo cotidiano que se realiza en las aulas. No porque desconozcamos el valioso esfuerzo de un número importante de docentes por impulsar "nuevos sentidos y significados" a su práctica pedagógica, sino porque también es cierto que el espacio del aula aparece abandonado en la mayoría de los casos a la rutina, al desarrollo de formas de trabajo establecidas. Sin embargo, el discurso de la innovación aparece como la necesidad de incorporar nuevos modelos, conceptos o formas de trabajo, sólo para justificar eso "que discursivamente se está innovando". No se generan tiempos para analizar los resultados de lo que se ha propuesto, no se busca sedimentar una innovación para identificar sus aciertos y límites (Díaz Barriga, 2005, p.10).

Si el Trabajo Social «construye su espacio profesional a partir de una problematización de las necesidades humanas, los procesos de colectivización y las formas sociales de satisfacción. Su intervención se concreta entre objetividades y subjetividades» (Universidad de la República, 2009) es fundamental que se incorpore en la formación, las habilidades que permitan una intervención critica, sólidamente fundamentada a partir de la teoría y con una práctica fundada en un proyecto ético-político.

Le enseñanza de grado y posgrado en Trabajo social implica la incorporación de la teoría social, como fundamento epistémico de la profesión, la promoción de habilidades y destrezas concretas de las formas de intervención desde su especificidad, lo que implica como plantea Carballeda (2005), que se deba entender que si el lugar privilegiado de inserción profesional es la vida cotidiana, esta debe ser pensada tanto desde la producción y reproducción del orden vigente como lo establece Heller (1987), así como a partir de la inserción de los sujetos en torno a la presentación de las personas (Goffman,1992). Formar profesionales del Trabajo Social involucra promover que estos no solo sean capaces de comprender la realidad, de investigarla, sino que además a la hora de intervenir lo hagan en búsqueda de una transformación del estado de cosas (Carballeda, 2005).

La intervención se origina a partir de algún tipo de demanda, institucional o espontánea, que se encuentra también atravesada por las diferentes construcciones discursivas que conllevan a una representación simbólica de la profesión o disciplina que la está llevando a la práctica. De ahí la importancia que adquiere la supervisión de prácticas pre profesionales y la riqueza que aporta a la formación la consolidación de los grupos durante dos años, en un mismo PI, desarrollando un área específica dentro de una misma organización o institución para consolidar la especificidad de la praxis del Trabajo Social. 
El objetivo de la enseñanza en la formación de grado implica que el/la estudiante desarrolle competencias para una práctica profesional organizada, incorporando el conocimiento de los fundamentos teórico-metodológicos y técnico-operativos de la disciplina, por lo cual se hace necesario la vigilancia epistemológica del proceso de enseñanza (de las estrategias empleadas previamente), así como del aprendizaje de los/las alumna/os, teniendo en cuenta el contexto intersubjetivo (el conocimiento ya compartido) cocreado como argumento para decidir estrategias y el modo de hacer uso de ellas (Díaz Barriga,2005).

La enseñanza desde el espacio teórico debe tematizar la relación del Trabajo Social con las diversas manifestaciones de la "cuestión social"13 vinculándola a los distintos espacios que ocupa la profesión, frente a las respuestas que brinda el Estado en términos de políticas públicas y a las propuestas de la sociedad. Otro eje de articulación para el proceso de enseñanza- aprendizaje es la vinculación con las diversas propuestas, perspectivas teóricas y fundamentos metodológicos que la profesión ha desarrollado en los distintos momentos históricos. Asimismo, la incorporación de especificidades dentro de la práctica profesional, vinculadas a áreas históricas de inserción profesional, enriquece la propuesta.

Una dimensión específica que no puede dejarse de problematizar cuando analizamos la perspectiva de los procesos de enseñanza desde la disciplina se vincula con el vínculo profesional que se establece entre el Trabajo Social y los sujetos, por lo que la dimensión ético-política es fundante y debe articularse con las concepciones teórico-metodológicas, aportando a la consolidación de la profesión a partir de la formación de las nuevas generaciones.

Si la cultura formal y pública que constituyen las disciplinas académicas es realmente un poderoso instrumento para el análisis de los distintos ámbitos de la realidad que rodean al alumno/a y para organizar de manera más racional y eficaz su intervención sobre los mismos, debe de hacerse evidente en el debate y foro de negociación que suponen los intercambios simbólicos en el aula (...)como instrumentos y herramientas de análisis y propuesta cuando realmente conecten con sus preocupaciones intelectuales, vitales $y$, al mismo tiempo, demuestren su superioridad con respecto a las preconcepciones vulgares previas (Sacristán, 1996,p.16).

Sin dejar de cuestionar los "ejercicios de poder" este llamado de atención deriva de los "sutiles mecanismos de dominación de un juego del lenguaje sobre otro -del discurso médico y jurídico sobre el social, del discurso económico y político sobre el cultural- dan origen a las continuas negociaciones tanto en el ámbito del ejercicio profesional como en el académico" (Matus, 1999, p.99).

13 Entendiendo cuestión social como el conjunto de problemas sociales, políticos y económicos que se generan con el surgimiento de la clase obrera en la sociedad capitalista, ver: Castel (1997), Netto (1997), lamamoto (1997). 
La necesaria exigencia de la calidad en la educación, la preocupación por una práctica de investigación, se implican en la tensión entre la pluralidad de espacios sociales de inserción profesional y la legitimación de su hacer. Es entre el cuestionamiento de la burocratización de la práctica y la capacidad de autorreflexión, que el Trabajo social intenta resolver a partir de la exigencia de la calidad en la educación, la investigación y la recuperación de su palabra en el debate público (González Laurino, 2008).

\section{Todo objeto de intervención es objeto de conocimiento}

La relación entre la investigación, enseñanza de la disciplina y práctica profesional ha sido por lo menos problemática a lo largo de la historia del Trabajo Social. A partir del ingreso a la Facultad de Ciencias Sociales (fruto de un largo recorrido hacia el acercamiento de la profesión a las ciencias sociales) se inicia un proceso que implicó una nueva relación entre la teoría social, el campo académico y el disciplinario.

La peripecia de la unidad teoría-práctica, desde su separación como esferas irreconciliables (práctica profesional versus academicismo) hasta el acercamiento a partir del primer plan de estudios (1992) y su profundización en el plan vigente (2009) es parte de un proceso desde el cual se avanza en la superación del debate teórico sobre la profesión: tecnología, ciencia social, enmarcado en las "posibilidades de desarrollo docente, investigativo, de producción de conocimiento [...] e impacta no sólo en el quehacer de los estudiantes y docentes directamente involucrados en el proceso de enseñanza-aprendizaje, sino en el colectivo profesional en su conjunto" (Gabin, 2009, p.86).

La investigación es una dimensión de la disciplina que conforma de manera indivisible el quehacer del Trabajo Social. Implica la generación de conocimiento sobre la realidad en la que además la profesión va a intervenir. La especificidad de la dimensión investigativa en la formación de grado y posgrado está fundada en la necesidad de generar conocimiento pertinente desde la especificidad disciplinaria. Es necesario "conocer" para intervenir, lo que implica un proceso de problematización de las demandas a la profesión, incluyendo la definición del problema y del objeto de intervención profesional a partir de un análisis crítico mediado por la teoría social, procedimiento imprescindible para la práctica profesional, implicada en la cotidianidad. 


\subsection{La investigación en Trabajo Social}

Pero la dimensión investigativa del trabajo social no se limita a este conocimiento para la intervención. La investigación social, la conformación de conocimiento novedoso y pertinente desde la disciplina no solo es posible, sino necesario. No desde una postura que plantee erróneamente una forma de conocimiento específico, pero sí desde la visión que se tiene desde una profesión históricamente vinculada a la realidad social.

Pensar la realidad social [...] donde pueden distinguirse, al menos dos dimensiones: la construcción de conceptos y la elaboración de una lógica original de funcionamiento que permiten explicar u comprender los fenómenos sociales [...] develar los mecanismos de dominación (Gutiérrez, 2012, p.17).

La conformación de los proyectos integrales como espacio que permite vincular la investigación y la práctica (tanto de docentes como de estudiantes) respecto a la articulación entre la formación específica, que incluye la práctica pre-profesional en organizaciones e instituciones, las prácticas profesionales de los trabajadores sociales inmersos en ella y los docentes desde su acumulación, es una oportunidad para la disciplina de generar conocimiento, tanto desde la conceptualización como desde el desarrollo de las prácticas profesionales.

Lo "real" no habla por sí mismo, siempre es abordado desde la teoría, por lo que investigar implica un recorte del objeto. Reflexionar sobre las formas de conocer implica también pensar qué empleo se le va a dar a ese conocimiento: El para "qué" y para "quién" se escribe y lo que se pretende describir, analizar o interpretar (Vasilachis, 2003). Es necesario explicitar los presupuestos epistemológicos, teóricos y metodológicos a la hora de plantear una investigación desde el Trabajo Social, sobre todo desde la dimensión ético-política de la profesión.

El hecho científico se construye, al enunciar el orden de los actos epistémicos, hay un proceso de ruptura que implica "que se construye contra la ilusión del saber inmediato", esto lleva a profundizar el rigor metodológico (Gutiérrez, 2012, p.23). Por ello, la labor de investigación implica la separación entre el saber del sentido común y el discurso científico, mediado por la teoría. Esto implica una necesaria vigilancia epistemológica, sobre todo porque el Trabajo Social tiene una suerte de acercamiento con su objeto de investigación, ya que fuertemente se vincula con los procesos de intervención «la familiaridad con el universo social constituye el obstáculo epistemológico por excelencia [...] produce continuamente concepciones o sistematizaciones ficticias, al mismo tiempo que sus condiciones de credibilidad» (Bourdieu, 2008, p.27).

Entender que la investigación es parte del quehacer profesional, que se constituye dentro del campo académico, donde el Trabajo Social debe "aceptar las 
reglas del juego" incorporando lo que históricamente se ha dejado en manos de otras disciplinas implica comprender al campo científico

\begin{abstract}
como sistema de las relaciones objetivas entre las posiciones adquiridas (en las luchas anteriores) es el lugar (es decir, el espacio de juego) de una lucha de concurrencia, que tiene por apuesta específica el monopolio de la autoridad científica, inseparablemente definida como capacidad técnica y como poder social, o, si se prefiere, el monopolio de la competencia científica, entendida en el sentido de capacidad de hablar y de actuar legítimamente (es decir, de manera autorizada y con autoridad) en materia de ciencia, que está socialmente reconocida a un agente determinado (Bourdieu, 1976, p.84).
\end{abstract}

La propuesta que se plantea desde el Departamento de Trabajo Social de la Facultad de Ciencias Sociales de la Universidad de la República implica incorporar la formación y el fortalecimiento de áreas de especialización tanto entre docentes e investigadores, como la posibilidad que se le plantea al estudiante de perfilar su desarrollo futuro.

La profundización de la investigación desde la disciplina se ve potenciada a partir de los PI. La ampliación del conocimiento del área de vejez y envejecimiento, se ha consolidado a partir de la acumulación de los docentes (presentación de ponencias, artículos en revistas y libros) así como los seminarios de tesistas que han culminado con más de cuarenta tesis de grado sobre la temática, así como de tesis de posgrado, maestría y doctorado desde la presentación del PI, consolidado un conocimiento fundado. El aporte que significa incorporar la mirada desde la disciplina amplía el conocimiento social sobre esta área temática que es de histórica inserción de la profesión y que no había contado con investigaciones propias, sino, que se ha nutrido de lo que otras disciplinas han pensado, analizado o sistematizado.

\title{
4 La formación específica en el campo gerontológico
}

A efectos de esta problematización se tomarán en cuenta las generaciones que han transitado su formación de grado desde la implementación del nuevo plan, esto es aquellas que iniciaron sus prácticas a partir del año $2011^{14}$. 
Estas generaciones se inscribieron específicamente a los distintos Proyectos Integrales y eligieron uno. Una vez incluidos en el PI "cuidado Humano" debieron optar por las diferentes áreas de intervención: infancia, discapacidad, vejez. En el año 2019 se han modificado algunas por lo que la nueva generación puede optar por vejez, discapacidad, generaciones y migración. Los estudiantes que eligen el área vejez luego son separados por centro de práctica (al igual que en las otras áreas) para ello se les presentan las características que tiene cada centro y los diversos horarios. La elección supone que el estudiante opte a partir de prenociones que son problematizadas a la hora de la selección.

En un primer momento de la práctica se les propone una pauta que incluye algunas categorías que fueron pensadas para poder generar información sobre las características del estudiantado que opta por el área.

1- Información patronímica (nombre, correo, teléfono)

2- Por qué eligió el PI

3- Por qué eligió el área

4- Se le realiza una pregunta abierta que implica adentrarse en las prenociones ¿Qué es la vejez?

5- Luego se le pregunta sobre las expectativa sobre la práctica

6- Se realiza una pregunta sobres si trabaja (para dilucidar horarios)

7- Finalmente se le pregunta por la elección del centro de práctica y sus razones.

Este formulario se aplica el primer día del curso y se vuelve a implementar al finalizar el segundo año de cursada.

El propósito inicial de la implementación del formulario fue conocer las características del estudiantado que optaba por el área de vejez y envejecimiento y que oficiara de tamiz sobre las características de la generación.

Habiendo trascurrido más de 8 generaciones de estudiantes que han culminado el proceso de prácticas en el área, se considera que configuran un insumo que permite medir las consecuencias que la formación específica en vejez y envejecimiento generan en la conformación de profesionales preocupados en la temática.

Se están procesando los datos recabados de estos instrumentos y se compararán con las trayectorias de los estudiantes que han optado por el área en cuanto a elección del tema para sus tesis de grado, así como para sus investigaciones. 


\section{Conclusiones}

En el proceso de práctica del área vejez y envejecimiento que se ha desarrollado desde el año 2009 hasta el presente se ha acompañado el egreso de ocho generaciones de estudiantes de la Licenciatura en Trabajo Social. Muchos de los participantes del área de vejez y envejecimiento han optado por realizar sus monografías de grado en la temática.

Se han procesado diversas problematizaciones en torno a la vejez, desde la surgida en la demanda concreta de grupos o personas, que implicaron discutir las condiciones materiales con que se transita, las redes sociales o las políticas públicas. Se han abordado en las monografías sobre la vejez diferentes tópicos que van desde la diversidad sexual a las características que insume el cuidado en situación de dependencia. Se ha iniciado una sistematización de las monografías de grado de los estudiantes que han transitado por el área, así como se están procesando los datos que surgen de otros instrumentos que se han aplicado en los cursos de formación permanente.

Una primera lectura de los documentos que se han generado a lo largo de 10 años de formación en la temática deja intuir que un acercamiento a las personas viejas promueve la disolución de los prejuicios y una necesidad de parte de los estudiantes de profundizar en la investigación a partir de sus tesis de grado.

El conocimiento a partir de la experiencia en las prácticas pre profesionales no solo deconstruye el viejísimo sino que genera prácticas vinculadas a la perspectiva de derechos.

Profundizar en el conocimiento que desde la disciplina se genera en torno a la vejez y el envejecimiento es parte de la construcción de una sociedad para todas las edades. 


\section{Referencias bibliográficas}

Baeza M. (1999). Metodologías cuantitativas en la investigación social y el tratamiento analítico de entrevistas. Revista Sociedad Hoy, 1(2-3) 49-60.

Beck, U. (1993). La invención de lo político. Buenos Aires: FCE.

Bourdieu, P. (1990). Sociología y Cultura. México: Grijalbo.

Bourdieu, P. (1997). Razones prácticas Sobre la teoría de la acción. Buenos Aires: Anagrama.

Bourdieu, P. (1988). Cosas Dichas. Barcelona: Gedisa.

Bourdieu, P. (2000). Sobre el poder simbólico. En Intelectuales, política y poder, Buenos Aires: Eudeba.

Bourdieu, P. (2008). El oficio de sociólogo. Buenos Aires: Siglo Veintiuno.

Carballeda, A. (2005). Lo social de la Intervención. El proceso de análisis en Trabajo Social. Revista Escenarios(38). Recuperado de https://www.margen. org/suscri/margen38/losoc.html\#inicio

Díaz Barriga, A. (2005). El enfoque de competencias en la educación. ¿Una alternativa o un disfraz de cambio? México: Perfiles educativos.

Dornell, Y. (2009). Lo visible y lo enunciable en la vejez. Área de Vejez y Trabajo Social, DTS-FCS-Udelar, Documentos de trabajo.

Gabín, B. (2009). Apuntes sobre el tema de la formación actual en Trabajo Social. Revista Fronteras, 5, 83-89.

Geertz, C. (1989). La interpretación de las culturas. Barcelona: Gedisa.

Giddens, A. (1987). Las nuevas reglas del método sociológico. Crítica positiva de las sociologías interpretativas. Buenos Aires: Amorrortu.

Giddens, A. (1995). Modernidad e identidad del yo. El yo y la identidad en la época contemporánea. Barcelona: Península.

Giddens, A. (1998). Consecuencias de la modernidad. Buenos Aires: Amorrortu.

Giddens, A. (2000). La transformación de la intimidad: Sexualidad, amor y erotismo en las sociedades modernas. Madrid: Cátedra.

Gimeno Sacristán, J. (1996). Comprender y transformar la enseñanza. Valencia: Morata.

Goffman, E. (1989). La presentación de la persona en la vida cotidiana. Buenos Aires: Amorrortu.

González Laurino, C. (2008). Políticas de identidad: la construcción colectiva de los sujetos en la Modernidad. Montevideo: Mimeo.

Grassi, E. (2003). Políticas y problemas sociales en la sociedad neoliberal. La otra década infame (I). Buenos Aires: Espacio. 
Gutiérrez, A. (2012). Las prácticas sociales. Una introducción a Pierre Bourdieu. Buenos Aires: Poliedros.

Heller, A. (1987). Sociología de la vida cotidiana. Barcelona: Península.

Jameson, F. (1992). El posmodernismo o la lógica cultural del capitalismo tardío. Buenos Aires: Paidós.

Matus, T. (1999). Propuestas contemporáneas en Trabajo Social. Hacia una intervención polifónica. Buenos Aires: Espacio.

Mauros, R. (2011). Área de vejez y Trabajo Social: Abordaje y Debate crítico. En: Dornell, T. Sande, S. Mauros, M., Stenphelet, S. Debates regionales en torno a la vejez: Una aproximación desde la academia y la práctica preprofesional.

Mauros, R. (2014). Área de Vejez y Trabajo Social: Una aproximación al debate en Uruguay. XIII Jornadas de Investigación de la Facultad de Ciencias Sociales, 1-7. Montevideo: Universidad de la República.

Netto, J.P. (2000). Método y teoría en las diferentes marices del servicio Social. En Borgianni, E y Monaño, C. (orgs). Metodología y Servicio Social hoy en debate. San Pablo: Cortez editora.

Netto, J.P. (1992). Capitalismo Monopolista e Serviço Social. Uma análise do Serviço Social no Brasil pós 64. San Pablo: Cortéz.

Quintero Velásquez, A. (s.f). La perspectiva de género y las nuevas organizaciones familiares. http://www.iin.oea.org/Cursos_a_distancia/cursoprojur2003/Bibliograf\%C3\%ADa\%20Mod.I/La\%20perspectiva\%20de\%20 g\%C3\%A9nero\%20y\%20las\%20nuevas\%20organizaciones\%20familiares.htm

Rozas, M. (2001). La Intervención profesional en relación con la cuestión social. El caso del Trabajo Social. Buenos Aires: Espacio.

Sande Muletaber, S. (2016). La vejez en Uruguay: una perspectiva crítica. Fronteras [en línea], (9), 139-151. Recuperado de http://cienciassociales.edu.uy/ departamentodetrabajosocial/wp-content/uploads/sites/5/2016/05/Sande. pdf

Sande Muletaber, S. (2015a). Los modelos de atención a la vejez en Uruguay. En Paola, J. Más mayores más derechos. Diálogos interdisciplinarios sobre la vejez. Buenos Aires: Edulp. Recuperado de http://www.ts.ucr.ac.cr/binarios/ libros/libros-000057.pdf

Sande Muletaber, S. (2015b). Estado de situación de las Políticas de Vejez: ¿Cómo trata el Estado a la vejez uruguaya. En Dornell, T., Sande, S., Muaros, $\mathrm{R}$ y Stemphelet, S. (Comp.) Debates Regionales en torno a la vejez: Un acercamiento desde la academia y la práctica pre-profesional. Montevideo: Udelar-FCS-DTS-AVYTS.

Sande Muletaber, S. (2014). La Sociedad Actual ¿Riesgo, multiculturalismo u ocultamiento de la explotación capitalista? Una visión desde la vejez y el envejecimiento. VIII Jornadas de Sociología de la UNLP. Recuperado de http:// www.memoria.fahce.unlp.edu.ar/trab_eventos/ev.4635/ev.4635.pdf 
Sautu, R., Boniolo, P., Dalle, P. y Elbert, R. (2005). Manual de metodología: construcción del marco teórico, formulación de los objetivos y elección de la metodología. Buenos Aires: Clacso.

Universidad de la República. (2009). Plan de Estudios de la Licenciatura en Trabajo Social. Montevideo: Universidad de la República.

Valles, M. (1997). Técnicas Cualitativas de Investigación Social. Reflexión metodológica y práctica profesional. Buenos Aires: Síntesis Sociológica.

Vasilachis, I. (2003). Pobres, pobreza, identidad y representaciones sociales. Buenos Aires: Gedisa.

Zizek, S. (1992). El sublime objeto de la ideología. México: Siglo XXI.

Zizek, S. (1998). Multiculturalismo, o la lógica cultural del capitalismo multinacional En Jameson, F. y Zizek, S. Estudios culturales, reflexiones sobre el multiculturalismo. Buenos Aires: Paidós.

Zizek, S. (2000). El espinoso sujeto: el centro ausente de la ontología política. Buenos Aires: Paidós.

Zizek, S. (2002) .¿Quién dijo totalitarismo? Valencia: Pretextos.

Dirección de correspondencia:

Sandra Sande

Doctora en Ciencias Sociales, opción Trabajo Social de la Udelar. Magister en Trabajo Social de la Udelar, Magister en Psicogerontología, Universidad Maimónides, Argentina, Licenciada en Trabajo Social, Licenciada en Sociología por la Udelar. Docente del departamento de Trabajo Social de la Udelar. Montevideo, Uruguay.

Contacto:

Sandrasande@hotmail.com

Esta obra se encuentra bajo una Licencia de Creative Commons Reconocimiento-NoComercial-Compartirlgual 4.0 Internacional 